\title{
EMPREENDEDORISMO INTENSIVO EM CONHECIMENTO NO BRASIL
}

\author{
Sonia K. Guimarães*
}

\begin{abstract}
Uma das surpresas da "nova economia" é o número crescente de micro, pequenas e médias empresas intensivas em conhecimento, assim como, de "cientistas-empreendedores" em economias periféricas, que, até recentemente, careciam de capacidade inovativa como, China e India (Saxenian, 2008). O Brasil enfrenta grandes desafios para integrar-se ao novo paradigma de desenvolvimento, se comparado a seus pares. Apesar disso, empresas intensivas em conhecimento despontam aqui de forma crescente. $\mathrm{O}$ artigo analisa resultados de uma pesquisa realizada entre micro, pequenas e médias empresas intensivas em conhecimento, localizadas em parques tecnológicos, nos estados do Rio Grande do Sul e de Santa Catarina. Os dados evidenciam que, mesmo restritas, observam-se algumas mudanças positivas na configuração do modelo empresarial no segmento investigado. Conclui-se, portanto, que as barreiras existentes não são intransponíveis, e o aprendizado já adquirido parece indicar que há possibilidades promissoras para as pequenas e médias empresas inovadoras, no Brasil.

PALAVRAS-CHAVE: pequenas e médias empresas intensivas em conhecimento, cientista-empreendedor, inovação, desenvolvimento econômico, sociedade do conhecimento.
\end{abstract}

\section{INTRODUÇÃO}

As transformações científicas, tecnológicas, econômico-sociais e culturais experimentadas nas últimas décadas (resultado de uma conjugação de fatores como, influência dos paradigmas digital, da biotecnologia e da nanotecnologia, liberação dos mercados e globalização), têm sido descritas e analisadas ad nauseum, pelo caráter revolucionário e extensivo nelas contido e pelas implicações sociais decorrentes.

Tais transformações impactam valores e orientações até então hegemônicos, como a concepção sobre crescimento econômico, relação entre produção do conhecimento e inovação, o fenômeno do cientista-empreendedor ou da pequena empresa intensiva em conhecimento. Esse último fenômeno tem sido considerado por alguns analistas como a novidade da economia capitalista atual (Cf. Neff; Wissinger,; Zukin, 2005).

* Doutora em Sociologia. Professora do Departamento de Sociologia e do PPG Sociologia da Universidade Federal do Rio Grande do Sul. Pesquisadora 1B CNPq

Av. Bento Gonçalves 9500. Cep: 91509-000. Porto Alegre RGS - Brasil. sonia21@ufrgs.br
As pequenas e médias empresas (até 49 e 249 empregados, respectivamente) intensivas em conhecimento têm sido consideradas como agentes relevantes na produção da inovação (Cf. Whittaker, 2009), contrariando a ideia prevalente, na maior parte do século XX, de que as grandes firmas eram, de fato, as forças-chave da inovação e, em consequência, do desenvolvimento capitalista. As grandes empresas tendem a seguir a trajetória usual da empresa: em uma economia em que predomina estabilidade e baixo grau de incerteza, as grandes empresas têm maior grau de eficiência, obtendo retornos do investimento em $\mathrm{P} \& \mathrm{D}$; entretanto, o aumento do risco pode resultar em processo de inércia que tenderia a limitar o desenvolvimento de inovações radicais. As pequenas empresas, por sua vez, em virtude de suas trajetórias diversificadas e por enfrentarem competição mais intensa, tendem a arriscar mais e a lidar melhor com a incerteza e a diversidade, o que contribuiria para levá-las a percorrer o caminho da produção de inovações. Nesse sentido, como afirmam Ruzzier et al. (2006), a percepção sobre o papel das peque- 
nas empresas tem sido alterada: se, no passado, eram vistas como vítimas, hoje, são vistas como players.

Por outro lado, como observou Saxenian, pequenas economias periféricas, como Israel e Taiwan, ou economias que até recentemente careciam de capacidade inovadora, como China e Índia, transformaram-se em polos dinâmicos em iniciativas empreendedoras e inovadoras (Cf. Saxenian, 2008).

O crescimento do empreendedorismo intensivo em conhecimento nos países emergentes está também associado à descentralização mundial da P\&D, o que foi possível, em grande parte, graças às tecnologias da informação e comunicação (TICs). A publicação Science and Engineering Indicators (National Science Board, 2010), dos Estados Unidos, mostra o novo mapa relativo à P\&D, em dimensão mundial: em 2007, América do Norte e União Europeia eram responsáveis por 63\% de US\$ 1,1 trilhão de investimentos mundiais na área, percentual inferior aos 71\% que detinham, em 1996. Os países da Ásia, do Pacífico, principalmente China, Japão e Coreia, cresceram, no período, de $24 \%$ para $31 \%$. A América Latina tem uma participação ainda pouco expressiva em investimentos em P\&D, participando apenas com 2.6\%.

A despeito da baixa participação da América Latina, o Brasil poderia integrar a lista de economias emergentes que apresentam número crescente de micro, pequenas e médias empresas intensivas em conhecimento, assim como, de "cientistas-empreendedores". Por ser um fenômeno relativamente recente, em uma economia que se ressente da cultura de inovação, torna-se necessário conhecer melhor a forma como está se processando o fenômeno que expressa uma mudança econômico-cultural na realidade brasileira.

Este artigo apresenta resultados de pesquisa realizada entre micro, pequenas e médias empresas intensivas em conhecimento, localizadas em parques tecnológicos, nos estados do Rio Grande do Sul e de Santa Catarina (vide detalhes sobre a metodologia adiante). O objetivo é investigar a forma como tais empresas se inse- rem no novo paradigma econômico-tecnológico, identificando agentes sociais relevantes para o desenvolvimento do processo de geração da inovação, destacando dificuldades e oportunidades.

\section{CONSIDERAÇÕES SOBRE O TEMA}

Segundo especialistas, crescimento e competitividade no âmbito econômico dependem, hoje, menos dos custos dos fatores clássicos de produção - terra, capital e trabalho - ou de alguma vantagem tecnológica, mas, sobretudo, do conhecimento, ${ }^{1}$ a verdadeira matéria prima capaz de gerar ideias novas (Cf. Romer, 1986). Romer, o renomado economista Americano, afirma que "The emerging economy is based on ideas more than objects..." (Time Magazine, 1997). O conhecimento seria responsável por mais da metade do PIB dos países desenvolvidos (Cf. OCDE apud Cavalcanti; Gomes, 2001), e a inovação ${ }^{2}$ - sempre que houver utilização de recursos com agregação de valor - torna-se a base do crescimento econômico. Isso porque os bens e serviços que dinamizam a produção o fazem através de transmissão ou condensação e incorporação de informação - em indústrias financeira e cultural, comércio, serviços administrativos, indústria de medicamentos e sementes geneticamente modificadas -, em que o principal valor agregado ao produto final contém baixo ou inexistente componente material, fenômeno que alguns denominam "desmaterialização da produção".

As indústrias produtoras de bens e serviços imateriais dependem de permanente inovação, e seu valor é avaliado considerando-se a

1 "Conhecimento: conjunto de afirmações organizadas sobre fatos ou ideias, apresentando julgamento racional ou resultados experimentais, transmitidos aos demais através de algum meio de comunicação, de alguma forma sistemática" (Bell, 1973, p.173, traduzido pela autora).

${ }^{2}$ O Manual de Oslo - documento publicado pela OCDE juntamente com a Eurostat, em 1992 (outras edições se seguiram, ampliando e aperfeiçoando as diretrizes inicialmente propostas), define inovação tecnológica como "the implementation/adoption of new or significantly improved production or delivery methods. It may involve changes in equipment, human resources, working methods or a combination of these." (OECD, 1996, p.9). 
potencialidade de criar novos bens e serviços aceitos pelo mercado.

Face à relevância do conhecimento e da inovação, considerados como fatores cruciais para alavancar o crescimento econômico, ganha força o argumento que sustenta a interdependência entre ciência e tecnologia, universidade e empresa. A interdependência entre ciência e tecnologia ocorre desde o início do século XX, quando do surgimento de indústrias como as de eletricidade, química e farmacêutica. Sustentava-se, entretanto, que conhecimento e inovação eram processos isolados. O desenvolvimento técnico era concebido como resultado de um processo linear (science-push), com origem no conhecimento gerado no âmbito da pesquisa básica (laboratório) e que, uma vez desenvolvido, chegava à empresa que o transformava em bens destinados ao mercado. A empresa era considerada um ator externo à dinâmica dos sistemas de C\&T de cada país (Cf. Viotti, 2008).

A perspectiva neo-schumpeteriana chamou a atenção para o caráter social e sistêmicointerativo do processo de inovação, concebido como uma rede de relações entre agentes sociais, incluindo relações interempresas, entre instituições de ensino e pesquisa, com a existência de infraestrutura pública e (ou) privada, economia nacional e internacional, assim como aspectos sócio-histórico-culturais locais, em que se incluem, dentre outros, características organizacionais, legais e normativas (Freeman, 1991; Lundvall, 1992).

Características próprias das novas áreas de conhecimento favorecem a emergência do novo paradigma, em razão da potencialidade comercial imediata de algumas tecnologias, como ocorre, por exemplo, com a engenharia genética - a intervenção sobre genes de organismos vivos com o objetivo de modificá-los - e a produção de medicamentos.

A ideia de interação entre universidade e empresa materializou-se, entre outros aspectos, no conceito de parques tecnológicos (e incubadoras), alguns deles localizados junto a universidades e (ou) centros de pesquisa.
Nos anos do pós-II Guerra, surgiram, nos Estados Unidos, experiências bem sucedidas de interação entre cientistas empreendedores, universidade e outros atores sociais, como David Hewllet e William Packard, egressos da Universidade de Stanford e criadores da hoje grande empresa Hewllet \& Packard. O Stanford Industrial Park é uma dessas experiências, que esteve na gênese da sociedade informacional, conforme destaca Castells (1996), tornando-se um modelo, imitado mundialmente. Criado em 1951, foi localizado junto ao campus da Universidade de Stanford, no estado da Califórnia - à época, região sem tradição industrial, cuja principal fonte de renda era, até então, a agricultura. Sua criação teve como objetivo tentar manter, na região, pessoal qualificado com formação em engenharias e ciências exatas, aproximando universidade e empresas com o objetivo de estimular a geração de inovação (Cf. Audy; Spolidoro, 2008). Alguns fatores teriam sido cruciais para o sucesso desse empreendimento, como a localização do Stanford Research Park no campus da Universidade de Stanford, o que facilitou a interação entre professores e alunos com empresários e pesquisadores de empresas instaladas no parque tecnológico; a existência de políticas governamentais que financiavam empresas de setores "portadores de futuro", como o setor da engenharia da computação; a legislação ajustada para facilitar a abertura e o fechamento de empresas; a existência de uma indústria de capital de risco consolidada (Cf. Audy; Spolidoro, 2008).

Algo similar ocorreu na chamada Rota 128, em torno de Boston e Cambridge, no estado de Massachusetts - região, então, em declínio econômico-, onde se localizavam importantes campi universitários, entre os quais o do Massachusetts Institute of Technology (MIT). Empresas ligadas aos setores de eletrônica (computadores, inteligência artificial) e biotecnologia floresceram na região, financiadas em boa parte pelo Departamento de Defesa do país.

A partir de então, o modelo de parques tecnológicos foi adotado em diferentes países, 
como alternativa de desenvolvimento econômico baseado na inovação.

À medida que a teoria da inovação avança, identificando o processo inovador como um processo de aprendizado, salienta-se a importância da interação com outros atores para que tal aprendizado ocorra, aliando-se elementos do ambiente externo com as capacidades da empresa. Apesar da manutenção da empresa como lócus da produção de inovação, o papel do ambiente inovador ganha importância. Destacamse, como agentes relevantes, o Estado, como incentivador para a criação de ambientes inovadores, e a universidade, como produtora de conhecimento e formadora de recursos humanos qualificados para atuação nas empresas (Cf. Dagnino, 2003).

Conforme já foi referido, estudos evidenciam que a transferência do conhecimento, desde o laboratório para a empresa até ao mercado, não é automática, mas constitui-se em processo complexo, cercado de riscos e incertezas, que tendem a ser maiores no caso de algumas novas áreas, como a biotecnologia, por exemplo. Por essa razão, o processo de inovação bem sucedido supõe a formação de redes de cooperação capazes de promover a interação entre os agentes-chave do processo: no nível acadêmico-científico, a busca de competências multidisciplinares e de interações com atores externos, como empresários, políticos e investidores; no nível da empresa, a necessidade de cooperação com o mundo acadêmico na busca de conhecimento e soluções, bem como com outras empresas e organizações. A figura do cientista empreendedor (surgimento das start-ups) torna-se, nessas condições, um agente importante para estabelecer o elo entre o bem intangível (produção de conhecimento) e a criação da inovação e sua disponibilização para o mercado. Tais iniciativas exigem apoios e soluções que não são apenas financeiros, mas também institucionais $^{3}$ (Cf. Viotti, 2008).

${ }^{3}$ O caso do Brasil é ilustrativo: o país avançou na produção de conhecimento; em 2008, contribuía com $2.2 \%$ da produção científica mundial, ocupando a $13^{\mathrm{a}}$ posição no ranking mundial.
A seção a seguir apresenta alguns aspectos que desafiam a realidade brasileira no contexto do novo paradigma da inovação e do desenvolvimento econômico-social do presente.

\section{BRASIL}

São bem conhecidos os desafios enfrentados pela realidade brasileira atual para ajustarse ao novo cenário econômico mundial, em que a inovação é a chave para o crescimento. Tais dificuldades são evidenciadas na comparação do país tanto com economias altamente industrializadas, quanto na comparação com os chamados países emergentes, como Índia e China (Cf. Viotti, 2008; Erber, 2010).

Vários fatores contribuem para tal defasagem, entre os quais a trajetória tecnológica que caracterizou a formação do parque industrial brasileiro, baseada no modelo de industrialização substitutiva de importações, sustentada pelo protecionismo que não incentivava o desenvolvimento de uma cultura de inovação.

Há consenso, hoje, em considerar os dispêndios em C\&T como fatores cruciais para o desenvolvimento baseado em setores intensivos em conhecimento. Países que detêm a liderança em P\&D, como Estados Unidos, Japão, Alemanha, França, por exemplo, apresentaram, no ano de 2008, dispêndio em P\&D superiores a 2,5\% do PIB (no Japão foi de 3,44\%). No Brasil, considerando-se o gasto público (governo federal e governos estaduais) e o gasto empresarial (empresas públicas e privadas) em C\&T, comparando-se os anos 2000 e 2008 temos, além de um valor bem abaixo do recomendado, crescimento praticamente inexistente.

Como mostra a Figura $1,{ }^{4} \mathrm{em} 2000$, os gastos públicos em P\&D, como percentual do PIB foram de $0,55 \%$, enquanto os gastos privados foram de $0,47 \%$, totalizando $1,02 \%$ (US\$17.9

${ }^{4}$ BRASIL - Ministério de Ciência e Tecnologia. Indicadores de
C\&T. 2010. Disponível em: www.mct.gov.br/index.php/ content/view/740.html?execview= Acesso em: 30 ago. 2011. 
Figura 1 - Tendências de GERD no Brasil, 2000-2008

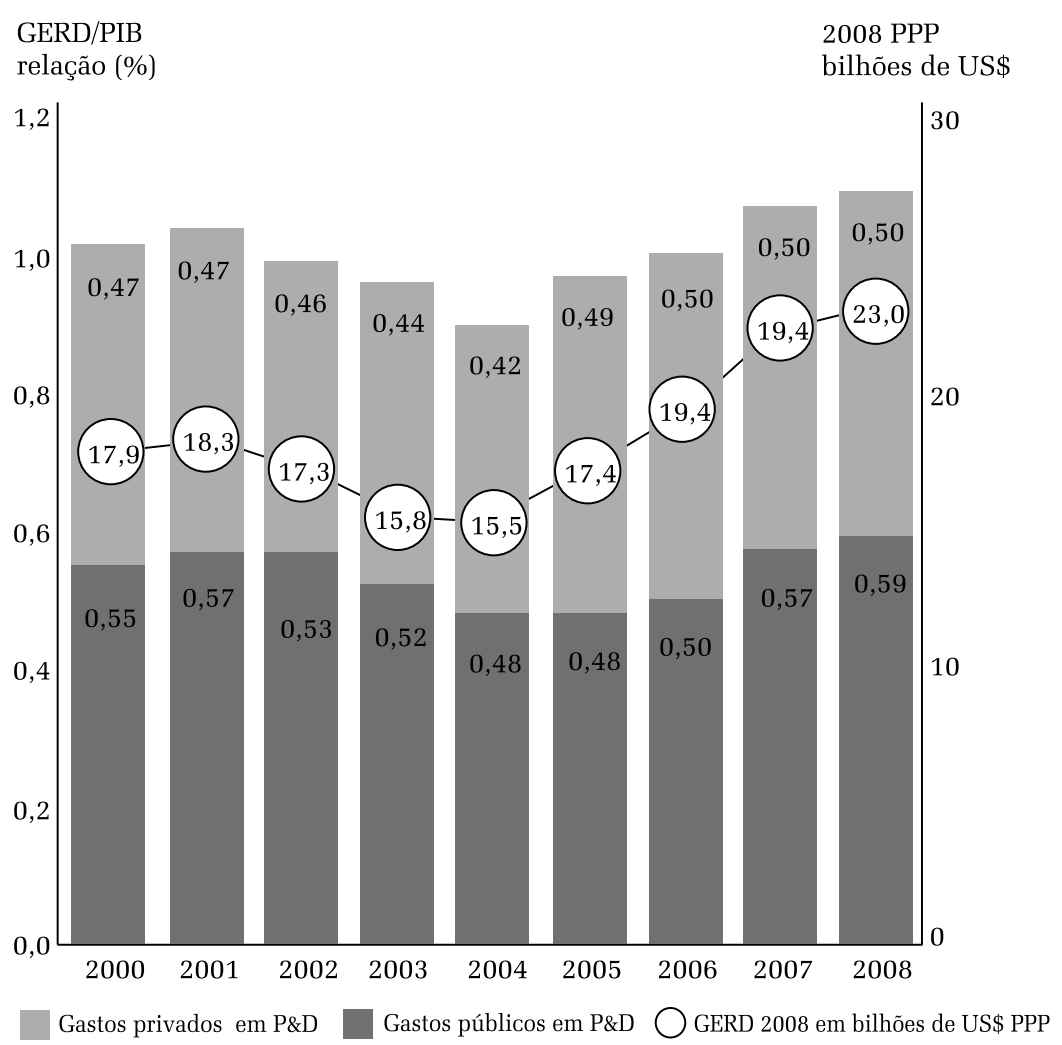

Observação: a P\&D privada inclui a P\&D privada sem fins lucrativos, por exemplo, os gastos em

Fonte: Ministério de Ciência e Tecnologia, Indicadores de C\&T, junho de 2010. pesquisa por universidades privadas $(0,02 \%$ do GERD).

vo, entre outros, de promover a transferência de conhecimento científico e (ou) tecnológico, visando ao desenvolvimento de capacidade tecnológica inovadora nas empresas, tendo em vista também a inserção tecnologicamente qualificada do Brasil no mercado internacional. Políticas como a dos Fundos Setoriais de Ciência e Tecnologia, visando ao desenvolvimento da pesquisa nos setores público e privado, incluindo o fomento à parceria entre universidade ou instituições de pesquisa e o setor produtivo, com apoio à inovação nas micro e pequenas empresas, bem como à criação de incubadoras e parques tecnológicos (Cf. Morais, 2008).

Resumidamente,

bilhões). Em 2008, o dispêndio público chegou a $0,59 \%$ do PIB (R\$ 26.900 bilhões) e os gastos privados alcançaram $0,50 \%$ totalizando (US\$ 23.013bi) 1,09\% do PIB. Constata-se que, no período de quase uma década, a taxa média de crescimento anual do dispêndio em C\&T foi insignificante - 0,07\%. Contudo, no mesmo período, a média de crescimento do PIB foi de 3,2, tendo sido especialmente expressiva nos anos de 2007 (6,09) e 2008 (5,16) (Cf. BRASIL, 2011).

Os dados apontados acima se refletem na carência de pessoal qualificado, em especial na área de $\mathrm{P} \& \mathrm{D}$, sobretudo, na área de ciências exatas e engenharia, fator indispensável para o desenvolvimento de setores intensivos em conhecimento (Cf. Lugones; Suarez, 2007).

Desde o final dos anos 1990, o país tem tido como foco alterar esse quadro, com o objeti- pode-se indicar uma série de incentivos para preencher os propósitos acima referidos. Em maio de 2000, foi criado o Projeto Inovar, com o objetivo de financiar pesquisadores para atuarem em empresas de base tecnológica, através do Programa de Apoio à Pesquisa em Empresas (PAPPE). Em novembro de 2003, foi lançado o documento Diretrizes de Política Industrial, Tecnológica e de Comércio Exterior (PITCE), baseado na concepção de integração do sistema produtivo com inovação tecnológica e competitividade no mercado exterior. Nele, destacam-se como linhas de ação: 1) a inovação e desenvolvimento tecnológico; 2) a inserção externa; 3) a modernização industrial. Por apresentarem fortes déficits comerciais e serem intensivas em tecnologia, foram definidas como áreas estratégicas as de: a) semicondutores; b) 
software; c) bens de capital; d) fármacos e medicamentos. Em dezembro de 2004, foi promulgada a Lei de Inovação, inspirada pelo BayhDole Act norte-americano e pela lei francesa de inovação, visando a estimular a participação de universidades e institutos de pesquisa públicos na produção de inovação. A lei regulamenta a transferência de tecnologias dessas instituições para empresas privadas, referindo-se explicitamente ao apoio a "ações de empreendedorismo tecnológico", ao mesmo tempo em que altera a base jurídica, liberando as instituições de C\&T para realizarem contratos remunerados com empresas incubadas, para uso de seus laboratórios (Cf. Morais, 2008; Viotti, 2008).

A Lei $\mathrm{n}^{\circ}$ 11.196, de novembro de 2005, a chamada Lei do Bem, instituiu incentivo fiscal às empresas que desenvolvem pesquisa tecnológica e contratam pesquisadores. Outros programas e mecanismos de crédito e subvenções têm sido criados recentemente, como a capitalização de fundos de investimento (venture capital, capital semente) em empresas inovadoras. Em maio de 2008, foi instituída a Política de Desenvolvimento Produtivo que privilegia áreas estratégicas como as TICs, a Nanotecnologia, a Biotecnologia, a Energia Nuclear, dentre outras. No que se refere às tecnologias de informação e comunicação, o objetivo é de posicionar o Brasil como produtor e exportador relevante de softwares e serviços de TI (Cf. BRASIL, 2009).

Entretanto, as deficiências acima referidas não são os únicos fatores a afetar o desenvolvimento do país. Outros fatores igualmente importantes inibem o bom funcionamento de negócios, como os apontados pela publicação da International Finance Corporation (IFC, 2011), ${ }^{5}$ que avaliou o desempenho do Brasil quanto a práticas que contribuem para promover a reali-

${ }^{5} \mathrm{O}$ relatório anual Doing Business Report apresenta a avaliação de 183 economias de todos os continentes, através da mensuração de nove variáveis consideradas fatores que contribuem para facilitar a realização de negócios. As variáveis consideradas são: "iniciar um negócio", "liberação para construção", "registro de propriedade”, "acesso a crédito", "proteção a investidores”, "pagamento de taxas”, "negócios além-fronteiras", "garantia de contratos" e "fechar um negócio”. zação de negócios. Em termos gerais, o país foi avaliado na $127^{\mathrm{a}}$ posição, dentre 183 economias, entre elas, México, China e Argentina, que se encontram, respectivamente, nas posições $5^{\mathrm{a}}, 79^{\mathrm{a}}$ e $115^{\mathrm{a}}$. No que se refere à variável "iniciar um negócio" (número de dias necessários para abrir um negócio), a informação é de 120 dias para o Brasil, enquanto na China são 38 dias, na Índia 29, na Argentina, 26 e no México 9 dias. Quanto à variável “acesso a crédito”, o Brasil está em $89^{\circ}$ lugar, comparado com China e Argentina, em $65^{\circ}$, Índia e México, em $32^{\circ}$ e $46^{\circ}$, respectivamente; quanto à variável "negócios além-fronteiras/internacionalização", Brasil está em $114^{\circ}$ lugar, a China em $50^{\circ}$ e o México $58^{\circ}$; quanto a "encerrar um negócio", Brasil posiciona-se na $132^{\circ}$ lugar, enquanto o México está em $23^{\circ}$ lugar, a China, em $68^{\circ}$ e a Argentina em $77^{\circ}$ lugar.

Em documento da OCDE, que apresenta índices construídos para medir o grau de obstáculos ao empreendedorismo, em uma escala de 0 a 6 , o Brasil registra 1.97, enquanto, na zona do Euro, o índice era 1.37 (OCDE, 2008).

Conforme indicam os dados, o Brasil apresenta um contexto pouco estimulante para a emergência de empreendimentos, como pequenas e médias empresas, comparando-se não apenas a países da OCDE e aos BRICs, mas também a alguns países da América Latina.

Por outro lado, as instituições brasileiras - como as de crédito, por exemplo - estão pouco preparadas para lidar com segmentos e aspectos imateriais, como software, marcas e internacionalização de ativos.

Diferenciando as situações nacionais países maduros e seus "sistemas de inovação" e países em processo de catching up e "sistemas de aprendizado" -, Viotti constatou, utilizando uma série de indicadores, que o sistema de aprendizado brasileiro, na primeira metade da década de 1990, poderia ser caracterizado como passivo, em oposição ao da Coreia que, na mesma ocasião, foi identificado como ativo (Viotti apud Erber, 2010, p. 56). Dez anos após, em estudo semelhante, o mesmo autor juntamente com 
coautores, afirmava ser "relativamente pobre o dinamismo do processo de inovação da indústria brasileira" e que "o aprendizado passivo parece ser dominante entre as empresas industriais brasileiras." (Viotti; Baessa; Keller apud Erber, 2010 p. 21, 56), indicando progresso praticamente inexistente na área.

Apesar do baixo desempenho tecnológico brasileiro, verificam-se avanços em algumas áreas, como agricultura, aeronáutica e exploração de petróleo em águas profundas. Dados comparados, relativos aos anos de 2000 e 2005, indicam que gastos médios por empresa aumentam entre pequenas e grandes empresas, na mesma proporção $(80 \%)$ e a metade desse percentual entre as médias empresas (Grynzpan apud Erber, 2010, p. 63).

\section{AS EMPRESAS INTENSIVAS EM CONHECI- MENTO INVESTIGADAS}

\section{Metodologia}

Os dados utilizados neste artigo são extraídos de uma pesquisa mais abrangente que investigou 81 empresas localizadas em incubadoras e em parques tecnológicos situados em campi universitários, no Rio Grande do Sul (UFRGS, PUC-RS, Unisinos, UCS) e em Santa Catarina (UFSC), escolhidas pelas experiências de cooperação entre universidade e empresa. A pesquisa de campo realizou-se a partir de um survey com a aplicação de questionário elaborado com base no instrumento utilizado pelo IBGE para a PINTEC - 2005, ${ }^{6}$ adaptado aos objetivos

${ }^{6}$ PINTEC/2005 é a primeira versão (a PINTEC iniciou em 1998) a trazer resultados para segmentos do setor de serviços com alta intensidade tecnológica: telecomunicações, informática e pesquisa e desenvolvimento. Com isso, a pesquisa, antes denominada Pesquisa Industrial de Inovação Tecnológica, passou a ser chamada de Pesquisa de Inovação Tecnológica. A PINTEC adota os critérios do Manual de Oslo, cujo objetivo é o de oferecer instrumentos capazes de identificar e mensurar os dados sobre inovação, visando a melhor avaliar e interpretar aquele processo (implementação de inovações nas empresas, motivação, tipos de inovação, implicações para o desempenho das empresas, incentivos e barreiras à inovação), em consonância com a relevância atribuída à inovação para o crescimento da produtividade e competitividade econômicas. da pesquisa. A aplicação dos questionários foi antecedida por pesquisas qualitativas anteriores (Cf. Guimarães; Azambuja, 2010; Guimarães et al., 2010; Blanco, 2009). ${ }^{7}$

Buscando maior homogeneidade de condições no que se refere às unidades de análise, o presente artigo baseia-se nos dados fornecidos pelas empresas instaladas nos parques tecnológicos investigados, no Rio Grande do Sul (TecnoPuc e Polo de Informática da Unisinos) e em Santa Catarina (Parque Alfa). Os informantes foram os empresários responsáveis pelas empresas investigadas. Todas as empresas de que se teve conhecimento na pesquisa exploratória dos parques foram contatadas, obtendo-se permissão para aplicação de questionários em 36 empresas que foram as investigadas (as recusas foram justificadas pelo caráter sigiloso das inovações em desenvolvimento). Os questionários foram aplicados apenas em empresas que já estivessem, há pelo menos um ano, operando nos parques, no período de aplicação - de fevereiro de 2009 a fevereiro de 2010. A análise dos dados realizou-se com o auxílio do software SPSS.

\section{Análise dos dados}

Como já foi referido acima, o crescimento do número de pequenas e médias empresas inovadoras é um fenômeno relativamente novo, que ganha destaque nas décadas finais do século XX. Os conceitos de inovação utilizados neste estudo referem-se à inovação de produto e de processo, tendo-se utilizado a conceituação proposta no Manual de Oslo (OECD, 1996), que é também seguida pela PINTEC/2005. Quanto à inovação de produto, ela se refere à introdução no mercado de um bem ou serviço tecnologicamente novo (as características básicas diferem significativamente dos produtos já produzidos pela empresa), ou substancialmente aprimorado (melhor desempenho ou um menor custo, através

${ }^{7}$ Para maiores detalhes, consulte Guimarães et al. 2010, disponível em http://www.ufrgs.br/ppgsocio. 
da utilização de matérias-primas ou componentes de maior rendimento) (IBGE, 2007). Quanto à inovação de processo, "refere-se à introdução de tecnologia de produção nova ou significativamente aperfeiçoada, assim como de métodos novos ou substancialmente aprimorados de oferta de serviços ou para manuseio e entrega de produtos." (IBGE, 2007, p.13).

As empresas investigadas (36 empresas) podem ser classificadas nas categorias micro, pequena e média, sendo que a mediana correspondia, em dezembro de 2008, a 30 pessoas ocupadas; o número menor de empregados encontrado foi de dois, e o maior de 180 empregados. Dezenove empresas investigadas envolviam-se com a produção de bens, e as demais (17 empresas) com serviços. A quase totalidade delas possuía capital controlador nacional, e os principais mercados eram: nacional (22 empresas) e estadual e regional (11 empresas).

A classificação "empresas inovadoras" atribuída às empresas investigadas é sustentada pelo seu desempenho: 31 empresas $(86,1 \%)$ responderam ter lançado produto (bem ou serviço) novo ou significativamente aperfeiçoado, no período de 2006-2008. Esse desempenho contrasta com o desempenho das empresas que empregam até 249 empregados, investigadas pela PINTEC 2008, cujo desempenho inovador (de produto ou processo) correspondia a $37,8 \%$ das empresas investigadas (Cf. IBGE, 2010). O desempenho inovador das empresas por nós investigadas era esperado, considerando-se que elas, localizadas em parques tecnológicos, têm compromisso contratual com a inovação.

Referindo-se ao principal produto inovador (bem ou serviço) lançado pelas empresas, dentre 31 respostas válidas, a maior parte delas indicou como sendo novo para o mercado nacional, mas já existente no mercado mundial (10 empresas) e como novo para o mercado mundial (9 empresas); 12 empresas informaram ser o principal produto novo para o mercado local (8 empresas) e novo para a empresa (4 empresas). Quanto à característica das inovações indicadas pelas empresas, destacam-se as relacionados ao desenvolvimento de software: software e sistemas não-customizados e software e sistemas customizados (9 e 5 empresas, respectivamente); componentes e peças e equipamentos para indústrias (6 empresas).

Tabela 1 - Principais produtos lançados pelas empresas

\begin{tabular}{l|c}
\hline Descrição do produto & $\begin{array}{c}\text { Principal produto } \\
\text { lançado pela } \\
\text { empresa no mercado } \\
\text { (2006-2008) }\end{array}$ \\
\hline $\begin{array}{l}\text { Páginas da Web } \\
\text { (Criação/Manut./Desenvolvimento) }\end{array}$ & 3 \\
\hline Software e Sistemas ñ customizados & 9 \\
\hline Software e Sistemas customizados & 5 \\
\hline $\begin{array}{l}\text { Peças, Componentes e Equipamentos } \\
\text { para Indústrias }\end{array}$ & 6 \\
\hline $\begin{array}{l}\text { Produtos, Testes e Ensaios Médicos e } \\
\text { Farmacêuticos }\end{array}$ & 3 \\
\hline Consultorias em TI e Representação & 0 \\
\hline Comercial & 5 \\
\hline Outro & 5 \\
\hline NA & 36 \\
\hline Total & \\
\hline
\end{tabular}

Comparando-se o principal produto inovador lançado e o principal produto em termos de faturamento (maior impacto no total de vendas líquidas internas nas empresas investigadas), constata-se que os produtos indicados como inovadores são também o principal produto quanto a faturamento (correspondendo a $40 \%$ ou mais do faturamento), ou seja, software e sistemas não-customizados, software e sistemas customizados e componentes, peças e equipamentos para indústrias (10, 8 e 6 empresas, respectivamente, dentre 36 respondentes). Esse dado reforça a classificação das empresas investigadas como empresas inovadoras bem sucedidas, visto que os produtos inovadores desenvolvidos têm maior impacto no total de suas vendas líquidas internas.

Outro dado que caracteriza a empresa como inovadora é o período de permanência do

${ }^{8}$ Não apresentou produto tecnologicamente novo ou substancialmente aperfeiçoado. 
principal produto no mercado, com as mesmas especificações. A maioria das empresas investigadas (18) respondeu ser o período de permanência no mercado de até 3 anos. Esses resultados sugerem que o produto principal necessita ser transformado e aprimorado de forma recorrente e contínua, visto que a competitividade das empresas depende do esforço para inovar. Esse comportamento pode ser considerado uma novidade na realidade das empresas brasileiras.

Em relação à inovação de processo, dentre as 33 empresas que responderam positivamente, 20 afirmaram ter realizado inovação já existente para o setor no Brasil (novo apenas para a empresa) e 13 afirmaram ter desenvolvido processo novo para o mercado nacional. Referindo-se à principal inovação de processo, dentre 24 respondentes, o número de empresas que afirma sê-lo novidade para a empresa é proporcionalmente maior (16), enquanto sete empresas afirmam ser o processo novo para o mercado nacio-

Tabela 2 - Grau de importância atribuído às parcerias

\begin{tabular}{l|c|c|c|c|c}
\hline \multirow{2}{*}{ Parceiros } & \multicolumn{5}{|c}{ Importância } \\
\cline { 2 - 6 } & Alta & Média & Baixa & $\begin{array}{c}\text { Não } \\
\text { relevante }\end{array}$ & Total \\
\hline Fornecedores & 8 & 5 & 2 & 9 & 24 \\
\hline Concorrentes & 2 & 7 & 5 & 9 & 23 \\
\hline Outra empresa do grupo & 3 & 0 & 0 & 7 & 10 \\
\hline Empresas de consultoria & 3 & 5 & 5 & 7 & 20 \\
\hline $\begin{array}{l}\text { Universidades e } \\
\text { institutos de pesquisa }\end{array}$ & 10 & 11 & 1 & 3 & 25 \\
\hline $\begin{array}{l}\text { Parque tecnológico e/ou } \\
\text { incubadora }\end{array}$ & 12 & 6 & 2 & 4 & 24 \\
\hline $\begin{array}{l}\text { Capacitação profissional } \\
\text { e assistência técnica }\end{array}$ & 4 & 7 & 3 & 1 & 24 \\
\hline
\end{tabular}
nal. Os tipos de inovações mais mencionados entre os 24 respondentes foi: "procedimentos organizacionais e métodos para controle de qualidade, produtividade e manutenção" e "processos com a finalidade de desenvolver um bem ou serviço". Em termos técnicos, as respostas sobre a natureza da inovação concentraram-se nas categorias "aprimoramento de um processo já existente" (13 empresas) e "novo para a empresa" (11 empresas), dentre as 24 respostas válidas.

A maioria das empresas (24 empresas), dentre respostas válidas, informou que o desenvolvimento de atividades inovadoras em geral (produto e de processo) realizou-se em cooperação ${ }^{9} \mathrm{com}$

9 Neste caso, “cooperação para a inovação" corresponde à participação em projetos de P\&D e outros projetos, sem implicar, necessariamente, benefícios monetários imediatos para as partes. outras instituições, empresas ou organizações. Vinte seis empresas declararam ter estabelecido pelo menos uma forma de cooperação com universidades, sendo que sete delas participaram em atividades de P\&D com universidades e institutos científicos; 13 empresas indicaram cooperação com clientes e fornecedores, em atividades de P\&D. Sobre o grau de importância dessas parcerias, foram consideradas de alta e média importância as parcerias com a universidade (21 empresas) e com clientes e fornecedores (17 empresas). 
municação (TICs). Conforme Kubota (2006, p.45), a constituição de um mercado de troca de informações, baseado em interação em tempo real de produtores e consumidores de informação, apresenta como resultado "interações individualizadas entre o consumidor - que busca soluções específicas ou conhecimento genérico para transformar o próprio conhecimento tácito em inovação - e fornecedor".

Quanto a outras importantes mudanças estratégicas e organizacionais, dentre 36 respostas válidas, destaca-se o número expressivo de empresas (20) que declararam ter implementado significativas mudanças na estratégia corporativa, técnicas avançadas de gestão da produção, da informação e ambiental (19) e significativas mudanças na estrutura organizacional (17). Esses dados sugerem que as empresas investigadas, tal como ocorre, em geral, com empresas inovadoras, tendem a adotar mudanças organizacionais, como novas formas de gestão, novos conceitos e métodos de gerenciamento e marketing.

Constatou-se que as empresas investigadas apresentam percentual elevado de inovação se comparado com o percentual observado pela PINTEC 2008 (IBGE, 2010), considerando-se apenas o conjunto das micro, pequenas e médias empresas. Entretanto, o caráter inovador das empresas por nós investigadas não foge ao que tem sido constatado por outros estudos: a maioria das empresas inovadoras investigadas segue trajetória próxima da imitação ou da inovação incremental, sem alcançar a mundial. A inovação incremental ou por imitação, ocorre por absorção e adaptação de tecnologias, cuja origem se encontra, na maioria das vezes, no exterior. Essa característica pode refletir, em parte, o chamado "market emptiness" - ausência, no mercado, de produtos de melhor qualidade e menor custo - o que torna fácil reconhecer a oportunidade para a inovação, mas que pode constituirse em limitação, ao obscurecer possibilidades de inovação radical. A inovação incremental é característica de países em processo de catching up, resultando, muitas vezes, da ausência de um valor cultural e, em consequência, de condições desfavoráveis a um ambiente verdadeiramente inovador. ${ }^{10}$ Incluem-se também fatores como ausência de uma cultura inovadora e baixo investimento em P\&D, conforme foi acima referido.

O nível de escolaridade dos empresários é outro aspecto que poderia contribuir para explicar o tipo de inovação da maioria das empresas inovadoras brasileiras. Em outra pesquisa por nós realizada, constatou-se que as poucas tentativas de inovação radical encontradas ocorreram em empresas cujos empresários possuíam formação pós-graduada $(\mathrm{PhD})$ e experiências acadêmicas e de inovação no exterior, sugerindo a possibilidade de haver uma relação positiva entre as variáveis em questão.

Entretanto, mesmo não alcançando a fronteira do conhecimento, a inovação gerada pela imitação ou através da combinação de conhecimento já existente exige das empresas conhecimento científico, conhecimento tácito e capacidade institucional e, por isso, deve ser reconhecida como um dado relevante em termos de avanço para o desenvolvimento do potencial inovador.

Quanto à atividade de Pesquisa e Desenvolvimento (P\&D), ${ }^{11}$ destaca-se o número de empresas pesquisadas que responderam ter desenvolvido, no período em estudo, atividades de P\&D: dentre 32 respostas válidas, 24 empresas afirmaram realizar atividades internas contínuas de P\&D. A atividade contínua de P\&D, no Brasil, tem sido uma prática pouco usual, em especial, em empresas privadas. Parece estar ocorrendo uma mudança de comportamento, resultado de uma resposta positiva aos incentivos governamentais, em especial no que se refere à implementação de incubadoras e parques tecnológicos como lócus que favorece a produção da inovação.

${ }^{10}$ No caso do Brasil, como já referido, cabe considerar a influência do modelo de industrialização baseado na substituição ou imitação de importações, que não favoreceu a inovação.

${ }^{11}$ No survey, a definição de atividade de P\&D utilizada pela PINTEC 2005 é: “... trabalho criativo, empreendido de forma sistemática, com o objetivo de aumentar o acervo de conhecimentos e o uso destes conhecimentos para desenvolver novas aplicações, tais como produtos ou processos novos ou tecnologicamente aprimorados" (IBGE, 2007, p.13). 
Tabela 3 - Grau de importância atribuído às fontes de informação empregadas para o desenvolvimento de inovação

\begin{tabular}{|c|c|c|c|c|c|}
\hline $\begin{array}{l}\text { Fontes de informação } \\
\text { empregadas para o } \\
\text { desenvolvimento da inovação }\end{array}$ & Alta & Média & Baixa & $\begin{array}{l}\text { Não } \\
\text { desen- } \\
\text { volveu }\end{array}$ & Total \\
\hline Atividade de P\&D & 25 & 8 & 1 & 2 & 36 \\
\hline Aquisição externa de P\&D & 2 & 3 & 5 & 25 & 35 \\
\hline Aquisição de software & 12 & 6 & 7 & 11 & 36 \\
\hline $\begin{array}{l}\text { Aquisição de máquinas e } \\
\text { equipamentos }\end{array}$ & 15 & 13 & 5 & 3 & 36 \\
\hline Treinamento & 16 & 7 & 6 & 7 & 36 \\
\hline $\begin{array}{l}\text { Projeto industrial e outras } \\
\text { preparações técnicas }\end{array}$ & 5 & 2 & 4 & 25 & 36 \\
\hline
\end{tabular}

Ao indicar o grau de importância de diferentes fontes de informação empregadas para o desenvolvimento da inovação, dentre 36 respondentes, 33 empresas indicaram a atividade de P\&D como de importância alta e média (24 e 7, respectivamente). Também foram consideradas como de alta e média importância a aquisição de máquinas e equipamentos (28 empresas), fornecedores de máquinas, equipamentos, componentes ou softwares (25 empresas); treinamento (23 empresas).

Quanto às atividades internas de P\&D desenvolvidas, os tipos mais mencionados foram: "estudo e desenvolvimento de técnicas, metodologias e softwares" (17 empresas) e "gestão e captação de informações" (9 empresas).

O desenvolvimento de atividades de P\&D em uma empresa é relevante, por estimular o processo de pesquisa, o que tende a aumentar significativamente as oportunidades de inovação bem sucedidas, favorecendo a participação no mercado. Essa parece ser também a percepção das empresas respondentes. Considerando os impactos das inovações de produtos (bens ou serviços) e processos implementados, os itens "melhoria da qualidade dos bens e serviços" e "manter a participação da empresa no mercado" concentraram as respostas dos que consideraram de "alta e média importância" (34 e 33 empresas, respectivamente). Observa-se ainda um número representativo de respostas que indicaram os itens "ampliar a gama de bens ou servi- ços ofertados" e "ampliar a participação da empresa no mercado" (29 e 27 empresas, respectivamente). A preocupação com o desempenho no mercado (em que se inclui "melhoria da qualidade dos bens e serviços) é revelada entre os itens mais indicados, quando as empresas avaliam o impacto das inovações. É interessante notar que o número de empresas que indicaram importância alta e média das inovações para a redução de custos de produção e do trabalho é menos significativo (16 e 15 empresas, respectivamente, responderam positivamente, dentre 36 respostas válidas), do que o das que indicaram "abrir, manter e ampliar a participação empresa no mercado". Ou seja, para a maioria das empresas respondentes, as inovações não visam ao rebaixamento de custos, mas, sobretudo, a melhor qualidade dos bens ou serviços (34 empresas atribuíram alta e média importância a esse item).

Contudo, o êxito das atividades de P\&D depende, em grande parte, do nível de qualificação científica - número de mestres e doutores das pessoas envolvidas. Observou-se número pouco expressivo de pós-graduados (mestres e doutores) ocupados em atividades internas de P\&D nas empresas investigadas: dentre 35 respondentes, apenas 4 empresas empregavam doutores (total de 7 doutores) e 21 afirmaram ter mestres como empregados. A hipótese era de que, em se tratando de empresas localizadas em campi universitários, esse número pudesse ser maior.

Os dados revelados pela pesquisa sobre a presença de mestres e doutores em atividades internas de P\&D corroboram as evidências já apontadas em outros estudos realizados no Brasil, como o estudo do Centro de Gestão e Estudos Estratégicos (CGEE, 2010), que realiza uma 
detalhada pesquisa sobre os pós-graduandos entre 1996 e 2006. O estudo evidencia que, dentre os doutores titulados no Brasil no período de 1996-2006, empregados em 2008, 80\% estavam empregados como "profissionais do ensino", o que demonstra o baixo aproveitamento de mestres e doutores em atividades ocupacionais distintas das acadêmicas propriamente ditas. Esse fato tende a ter implicações tanto nas interações entre empresas e universidades quanto na prática de pesquisa e, consequentemente, no desempenho das empresas quanto à produção de inovações baseadas em conhecimento científico (Cf. Gibbons; Johnston apud Velho, 2007).

Segundo Velho (2007), estudos recentes sugerem a existência de relação positiva entre o número de doutores envolvidos em P\&D na empresa e output tecnológico. Essa pode ser uma das explicações para o fato de que as inovações desenvolvidas pelas empresas investigadas não ultrapassam o nível incremental, destinada ao mercado nacional.

Contudo, o baixo número de pesquisadores nas empresas pode refletir tanto ausência de reconhecimento do caráter estratégico do conhe-

Tabela 4 - Tipos de proteção solicitadas pelas empresas

\begin{tabular}{|c|c|c|}
\hline Tipo de proteção & $\mathbf{N}$ & $\%$ do total \\
\hline Patente no Brasil & 5 & 13,9 \\
\hline Patente no exterior & 1 & 2,8 \\
\hline Patente de invenção & 3 & 8,3 \\
\hline Patente de modelo de utilidade & 4 & 11,1 \\
\hline Registro de desenho industrial & 1 & 2,8 \\
\hline Marcas & 20 & 55,6 \\
\hline Direitos autorais & 4 & 11,1 \\
\hline Complexidade no desenho & 5 & 13,9 \\
\hline Segredo industrial & 9 & 25,0 \\
\hline $\begin{array}{l}\text { Tempo de liderança sobre os } \\
\text { competidores }\end{array}$ & 6 & 16,7 \\
\hline Método de proteção de inovações & 5 & 13,9 \\
\hline $\begin{array}{l}\text { Acordos e/ou contratos de } \\
\text { confidencialidade }\end{array}$ & 2 & 5,6 \\
\hline Criptografia e/ou proteção por software & 1 & 2,8 \\
\hline
\end{tabular}

cimento para o avanço dos negócios, quanto a preparação pouco adequada dos cientistas para operarem em atividades de P\&D.

No que se refere a depósito de patente, ${ }^{12} \mathrm{a}$ grande maioria das empresas respondeu negativamente sobre a solicitação de depósito de patente (30), ou utilização de patente de invenção (33), de registro de desenho industrial (35), direitos autorais (32), segredo industrial (27), criptografia e (ou) proteção por software (35). Quanto a mecanismos de proteção da inovação, a utilização de marcas foi o mais indicado, com 20 empresas respondendo positivamente.

O tipo de inovação (incremental) de produtos e serviços das empresas investigadas tende a restringir o mercado, em especial o de exportação. Quando se examina o mercado principal das empresas investigadas, tanto produtoras de bens como de serviços, a maioria (22 casos em 36) afirma ser o nacional, sendo que 11 empresas indicaram o estadual e o regional como principal mercado. Considerando-se a promulgação pelo governo de uma série de incentivos com o objetivo de posicionar o Brasil como produtor e exportador de inovações, observa-se que esse esforço ainda não produziu os resultados esperados.

No que se refere à exportação, ela é considerada uma das características que distingue a empresa inovadora das nãoinovadoras, visto que as empresas que inovam tendem a contar com maior chance de sucesso no mercado externo, o que, por sua vez, tende a contribuir como fonte de informação e estímulo para aperfeiçoar a inovação existente. Por exemplo, através de exigências técnicas em relação ao produto, estabelece-se um círculo virtuoso que favorece a empresa.

As bases da Política Industrial, Tecnológica e de Comércio Exterior (PITCE) ${ }^{12} \mathrm{O}$ “depósito de patente”, apesar de ser um indicador utilizado por órgãos oficiais, é considerado por alguns estudiosos como de baixa utilidade: em áreas como a de software, a concessão de patente é, em geral, mais demorada do que a vida do produto. Por outro lado, no Brasil, o processo de concessão de patente é muito demorado, burocratizado e caro, o que desestimula possíveis interessados. 
foram divulgadas no final de 2003, definindo como objetivo: "aumento da eficiência da estrutura produtiva, aumento da capacidade de inovação das empresas brasileiras e expansão das exportações" (BRASIL, 2003, p.2). Algumas ações nessa direção já foram implementadas, como a marca BrBiotec, criada para reforçar a identidade e o desempenho das firmas brasileiras, globalmente, na área da Biotecnologia.

Os dados do survey em análise mostram um número muito baixo de empresas que afirmaram ter exportado, em 2008: são 6 empresas, dentre 10 respostas válidas (considerando-se as 36 respondentes). A resposta que apresenta resultado estatístico mais significativo é a que indica a exportação de "produtos tecnologicamente novos ou significativamente aprimorados para o mercado mundial". A constatação corrobora a tese de Negri (2005) de que as inovações de nível nacional ou mundial exercem maior influência na inserção das empresas em mercados internacionais, em comparação com as inovações que ocorrem apenas no nível da empresa.

O baixo grau de internacionalização das pequenas e médias empresas inovadoras brasileiras foi também observado no setor de biotecnologia. Pesquisa realizada em 2008, entre 252 empresas, constatou que apenas $11,2 \%$ dos respondentes declararam manter atividade exportadora constante, enquanto $22,4 \%$ a mantinham ocasionalmente (Cf. BioMinas, 2009).

Estudos demonstram que há estreita relação entre exportação e inovação intensiva em conhecimento. As empresas que exportam beneficiam-se da transferência de conhecimento e da cultura empresarial de outras empresas e países; ao mesmo tempo, para garantir competitividade em mercados externos, tendem a investir mais em P\&D e em qualificação de mão de obra.

Segundo Tironi e Cruz (apud Erber, 2010), as empresas exportadoras teriam 3,5 vezes mais chances de inovar de modo radical do que uma empresa voltada para o mercado estadual ou regional.

Os dados sobre cooperação das empresas indicam mudança relevante no seu comporta- mento, considerando a baixa tradição existente, sobretudo nas privadas, de cooperação com universidades e institutos de pesquisa, instituições que podem constituir-se em parceiras estratégicos na busca de novos conhecimentos e que permitam avançar na natureza da inovação.

Ao apontar os fatores que dificultam a inovação, as empresas investigadas indicaram como sendo de alta e média importância: elevados custos da inovação (23); escassez de fontes apropriadas de financiamentos (21); riscos econômicos excessivos (16). Em um momento de razoável disponibilidade de recursos governamentais para a inovação, surpreende a indicação de "escassez de financiamentos” como fator que dificulta a inovação.

No caso do Brasil, há mecanismos nas áreas de crédito e subvenções para atender às necessidades das micro e pequenas empresas inovadoras, como os programas Pró-Inovação e Pappe, programas Juro Zero, Cooperação Finep/Sebrae/ ICTs, Subvenção a Empresas e a concessão de subvenção para a contratação de pesquisadores nas empresas (Morais, 2008, p.99-100). O presidente da Finep (Financiadora de Estudos e Projetos), na época Luís Manuel Rebelo Fernandes, declarou, em entrevista ao jornal Folha de S. Pau$l o$ (edição de 12.09.2009) que fora destinado $\mathrm{R} \$ 41$ bilhões, através do Ministério de Ciência e Tecnologia (MCT), para aquele tipo de investimento e que boa parte do recurso não fora utilizado.

Os dados da amostra relevam que a fonte principal de financiamento para as inovações nas empresas investigadas são recursos próprios: dentre 34 empresas respondentes, 20 declararam arcar elas próprias com $100 \%$ dos recursos investidos em suas atividades inovadoras; 10 informaram utilizar-se de recursos públicos, porém, 7 delas os utilizaram em valores de apenas até $20 \%$ do total; apenas 2 empresas utilizam-se de valor maior do que $50 \%$ dos recursos necessários à inovação.

Vários fatores podem ter contribuído para explicar esse resultado: ausência de pesquisadores (mestres e doutores) nas empresas, falta de consultoria adequada, falta de capilaridade das 
agências de fomento, assim como temor de endividamento por parte dos empresários, em razão dos altos juros na economia brasileira, ou temor de possíveis imposições por parte dos financiadores, o que restringiria a "autonomia" da qual muitos empresários se gabam de desfrutar.

\section{CONCLUSÕES}

O argumento desenvolvido neste artigo é que são observadas, nas últimas décadas, mudanças significativas no paradigma econômico, sustentadas, em grande parte, pelas revoluções das tecnologias da informação e comunicação, da biotecnologia, nanotecnologia e ciências cognitivas. Esse fato contribui para a crescente ampliação do mercado e da demanda por setores intensivos em conhecimento, e impõe novas bases para o desenvolvimento e o crescimento econômico. O Brasil enfrenta grandes desafios para se integrar ao novo modelo, se comparado a seus pares - países de economia emergente, em especial, China e Índia , em razão de diversas deficiências. Entre elas, destacam-se a carência de educação de qualidade e de pessoal qualificado em áreas tecnológicas, exigências cruciais para o desempenho das novas atividades da chamada "economia do conhecimento", além da cultura acadêmica e empresarial, e de valores de natureza incremental) introduzido pelas empresas investigadas sugere que sua localização em parques tecnológicos, situados em campi universitários, pode tê-las influenciado positivamente, cumprindo os objetivos para os quais foram criados.

Os dados sugerem também que, em geral, os principais produtos inovadores em número significativo de empresas investigadas foram bem sucedidos comercialmente, visto que constituem também o principal produto quanto a seu faturamento líquido. Por outro lado, a presença significativa de atividades de P\&D nas empresas investigadas, com o objetivo de produzir conhecimento a ser aplicado na produção de bens e serviços, bem como a importância que lhe é atribuída, constitui uma novidade, no Brasil, considerando-se a ausência de tradição dessas atividades mesmo em se tratando de grandes empresas, tanto nacionais quanto estrangeiras. Por outro lado, o foco em P\&D entre as empresas investigadas favoreceu a presença de arranjos cooperativos, como redes de interação, incluindo relações entre universidade e empresa e entre empresas e clientes e fornecedores, permitindo o acesso e identificação de informação e recursos necessários ao desempenho de suas atividades inovadoras. Constatou-se que o esforço para inovar incorporou-se à prática das empresas, constituindo-se em atividade recorrente e contínua. Esse comportamento foge à tradição da realidade das empresas brasileiras.

No entanto, persistem, no Brasil, dificuldades que terão que ser vencidas talvez no médio prazo. Dentre as mais prementes estão: a carência de pessoal qualificado, sobretudo, na área de ciências exatas e engenharia; o baixo investimento em CT\&I; as características de certas instituições brasileiras - como as de crédito, por exemplo - que estão pouco preparadas para lidar com segmentos e aspectos imateriais, como softwares, marcas e internacionalização de ativos; e os fatores inibidores do bom funcionamento de negócios, como os apontados pela publicação Doing Business Repor - Making a difference for entrepreneurs (World Bank \& International Finance Corporation, 2011). Não se pode também deixar 
de fazer referência ao modelo de produção acadêmica no Brasil, excessivamente distanciado dos problemas relacionados à inovação.

A pesquisa sociológica tem muito a contribuir nessa área, buscando analisar de forma mais apurada esse processo. Sabe-se que os processos de inovação diferem muito de setor para setor quanto a desenvolvimento, taxa de mudança tecnológica, interações e acesso ao conhecimento, assim como em termos de estruturas organizacionais e fatores institucionais. Alguns setores são caracterizados por rápidas mudanças e inovações radicais, outros por mudanças menores e incrementais. Por exemplo, no setor de biotecnologia, as pequenas e médias empresas são atores relevantes, competindo, cooperando ou sendo adquiridas com as grandes empresas. $\mathrm{O}$ processo de inovação, nesse setor, está submetido a regulamentações e demandas institucionais. No setor de software, a inovação se desenvolve tanto na produção padronizada como na personalizada. Nesse caso, observa-se maior interação entre usuário e produtor, assim como entre as redes global e local, assim como grande mobilidade de recursos humanos qualificados (Cf. Malerba, 2005).

Finalmente, cabe deixar claro que a produção de inovações resulta de uma articulação complexa e não-linear de competências específicas. Como bem afirmou Viotti (2008), não há medidas políticas ou modelos internacionais $a$ priori definidos como capazes de responder adequadamente à questão sobre produção de inovação. Aplicar o conhecimento científico, na maioria das vezes, demanda adaptações e soluções de difícil encaminhamento e que dependem de apoios institucionais que não são apenas financeiros. A empresa, considerada como agente central da inovação, é apenas uma parte de um sistema mais amplo, constituído por uma rede de relações entre agentes sociais, própria de um país ou região (incluindo relações entre empresas e entre instituições de ensino e pesquisa), pela existência de uma infraestrutura pública e (ou) privada, pela economia nacional e internacional, assim como por aspectos sócio-histórico-culturais locais, em que se incluem, dentre outros, as características organizacionais, legais e normativas (Cf. Freeman, 1991; Lundvall, 1992).

Nesse sentido, embora os dados apontem para o fato de que o ambiente brasileiro ainda se ressente de uma verdadeira cultura inovadora, também parecem sugerir que as barreiras existentes não são intransponíveis, e o aprendizado já adquirido parece indicar que há possibilidades promissoras.

(Recebido para publicação em 10 de setembro de 2011) (Aceito em 03 de dezembro de 2011)

\section{REFERÊNCIAS}

AUDY, Jorge; SPOLIDORO, Roberto. Parque científico e tecnológico do PUCRS. Porto Alegre: EDIPUCRS, 2008.

BALBACHEVSKY. Entraves e incentivos para o desenvolvimento de sinergias entre universidade e sociedade na produção do conhecimento: a experiência da América Latina. In: ENCONTRO ANUAL DA ASSOCIAÇÃO NACIONAL DE PÓS-GRADUAÇÃO EM CIÊNCIAS SOCIAIS-ANPOCS, Mesa Redonda: Produção do conhecimento científico e inovação,34, Caxambu, 2010.

BELL, Daniel. The coming of post-industrial society: a venture in social forecasting. New York: Basic Books, 1973.

BIOMINAS Foundation. Estudo das Empresas de Biociências, Brasil, 2009. Disponível em: http://win.biominas.org.br/ biominas2008/File/estudo\%20setorial\%20site.pdf . Acesso em: jun. 2011.

BLANCO, Gabriela Dias. Inovações tecnológicas e a cultura inovativa: estudo de caso sobre a incubadora Celta, Florianópolis, SC. 2009. Monografia (Conclusão) - Bacharelado em Ciências Sociais da UFRGS. Porto Alegre, 2009.

BRASIL. PITCE. Política Industrial, Tecnológica e de Comércio Exterior Brasília, 2003.

BRASIL. Ministério da Ciência e Tecnologia. Indicadores nacionais de ciência e tecnologia. Comparações internacionais. Disponível em: http://www.mct.gov.br/index.php/ content/view/740.html? execvie= Acesso em: 20 jun. 2011.

BRASIL. Ministério do Desenvolvimento, Indústria e Comércio Exterior. Inovar e investir para sustentar o crescimento. 2009. Disponível em: http://www.desenvolvimento. gov.br/pdp/arquivos/destswf1224095287.ppt\#461,1> Acesso em: jul. 2011.

CASTELLS, Manuel. The rise of the network society: the information age: economy, society and culture. [S.l.], Blackwell, 1996.

CAVALCANTI, Marcos; GOMES, Elizabeth. A sociedade do conhecimento e a política industrial brasileira. In: CASSIOLATO, José Eduardo et al. O futuro da indústria: oportunidades e desafios : a reflexão da universidade. Brasília: MDIC/STI, 2001. p.245-267.

CENTRO DE GESTÃO E ESTUDOS ESTRATÉGICO. CGEE. Avaliação de políticas de ciência, tecnologia e inovação: diálogo entre experiências internacionais e brasileiras. Brasília: 2008.

DAGNINO, Renato. A relação universidade-empresa no Brasil e o argumento da Hélice Tripla. Revista Brasileira de Inovação, Campinas, Unicamp,v.2 n.2, p.267-307, 2003. 
DE NEGRI, Fernanda. Inovação tecnológica e exportações das firmas brasileiras. In ENCONTRO NACIONAL DE ECONOMIA, ANPEC. Anais.... Natal: ANPEC, 2005.

Padrões tecnológicos e de comércio exterior das firmas brasileiras. In: ; SALER NO, M. (Org.) Inovações, padrões tecnológicos e desempenho das firmas industriais brasileiras. Brasília: IPEA, 2005.

ERBER, Fabio Stefano. Inovação tecnológica na indústria brasileira no passado recente: uma resenha da literatura econômica. Textos para Discussão CEPAL/IPEA, Brasília, n.17 2010.

FREEMAN, C. Networks of innovators: a synthesis of research issues. Research Policy, [S.l.], Elsevier, n.20, 1991

GOEDHUYS, M.; VEUGELERS, R., Innovation strategies, process and product innovations and growth: Firm-level evidence from Brazil. Structural Change and Economic Dynamics, [S.l.], Elsevier, p.1-26, 2011.

GRYNZPAN, F. O investimento privado em P\&D pela indús tria de transformação brasileira: avaliação de políticas de ciência, tecnologia e inovação: diálogos entre experiências estrangeiras e brasileira. Brasília: CGEE, 2008.

GUIMARÃES, Sonia M. K. et al. Construção da inovação através de redes de cooperação universidade-empresa: análise das iniciativas e estratégias de cooperação no Rio Grande do Sul. Relatório científico CNPq. ago. 2010. Disponível em: www.ufrgs.br/ppgsocio/Relat\%C3\%B3rio\%20 Cient\%C3\%ADfico\%202010.pdf. Acesso em: jun. 2011.

(Org.) Grupo de pesquisa trabalho na sociedade contemporânea. Disponível em: www.ufrgs.br/ppgsocio. Acesso em: 10 jul. 2011

; AZAMBUJA, Lucas Rodrigues. Empreendedorismo high tech no Brasil: condicionantes econômicos, políticos culturais. Sociedade e Estado, Brasília,UnB, v.25 n.1, jan/ abr. 2010

IBGE. Pesquisa de Inovação Tecnológica 2005 - PINTEC 2005. Ministério do Planejamento, Orçamento e Gestão. Rio de Janeiro, 2007.

Pesquisa Industrial de Inovação Tecnológica 2008 - PINTEC 2008. Ministério do Planejamento, Orçamento Gestão. Rio de Janeiro, 2010.

IFC. International Finance Corporation Doing Business Report. Making a difference for entrepreneurs. 2011. Disponivel em: www doingbusiness.org/ /media/ fpdkm/ doing\%20business/documents/profiles/country/db11/ bra.pdf. Acesso em: jun. 2011.

đ KUBOTA, Luis. A inovação tecnológica das firmas de serviços no Brasil. In: DE NEGRI, João; KUBOTA, Luis. Estrutura e dinâmica do setor de serviços no Brasil. Brasília: IPEA, 2006.

LUGONES, G.; SUAREZ, D., National Innovation Systems in Brazil and Argentina: key variables and available evidence. In: DE NEGRI, J.; TURCHI, L.M. (Ed.) Technological Innovation in Brazilian and Argentine firms. Brasilia: IPEA, 2007.

LUNDVALL, B. (Ed.) National systems of innovation towards a theory of innovation and interactive learning London: Pinter, 1992.

MALERBA, F. And the evolution of industries. Working Paper, n.172, Milan, It: CESPRI University, 2005.

MORAIS, J. M. de. Uma avaliação de programas de apoio financeiro à inovação tecnológica com base nos fundos setoriais e na lei de inovação. In: DE NEGRI, J. A.; KUBOTA, L. C. (Org.) Políticas de incentivo à inovação tecnológica no Brasil. Brasília: IPEA, 2008.

NATIONAL SCIENCE BOARD. Science and Engineering Indicators 2010. Arlington, VA: jan. 2010.

NEFF, G.; WISSINGER, E.; ZUKIN, S. Entrepreneurial la-

bor among cultural producers: 'cool' jobs in 'hot' industries. Social Semiotics, [S.1.], Routledge,v.15, n 3, p.307-34, 2005 OCDE, Indicators of product market regulation, 2008.

Programme for International Student Assessment PISA. 2009. Disponível em: http://dx.doi.org/10.1787/ 888932343342http://dx.doi.org/10.1787/888932343342. Acesso em: 18 jun. .2011.

Tackling inequalities in Brazil, China, India and $\overline{\text { South A }}$ frica - the role of labour market and social policies, 2010.

OECD. Manual de Oslo: OECD proposed guidelines for collecting and interpreting technological innovation data. Paris: 1996.

PIRES-ALVES, C. Rocha. Testing the Schumpeterian hypotheses for the Brazilian manufacturing industry. In ENCONTRO NACIONAL DE ECONOMIA, 36, Salvador, Anpec, 2008.

RODRIGUEZ et al. OCDE Tackling Inequalities in Brazil, China, India and South Africa - the role of labour market and social policies, 2010.

ROMER, Paul. Increasing returns and long run growth. The Journal of Political Economy, [S.1.], v.94, n.5, oct. 1986. Disponível em: www.jstor.org/stable/i331956. Acesso em: jun. 2011

RUZZIER, M.; HISRICH, R. D.; ANTONCIC, B. SME internationalization research: past, present and future. Journal of Small Business and Enterprise Development, [S.1], v.13, n. 4, p.476-497, 2006.

SALERNO, M. S. A política industrial, tecnológica e de comércio exterior do governo federal. Parcerias Estratégicas, Brasília, CGEE, n.19, 2004.

SAXENIAN, Anna Lee. Venture capital in the "periphery": the new argonauts, global search and local institution building. Economic Geography, [S.l.], v.84, n.4, p.379-394, 2008. Disponível em: http://people.ischool.berkeley.edu/ anno/Papers/venture_capital_in_the_periphery.pdf. Acesso em: jun. 2011.

THE WORLD BANK \& THE INTERNATIONAL FINANCE CORPORATION. Doing Business 2011: Making a Difference for Entrepreneurs, Washington, DC, 2011.

TIME MAGAZINE. TIME's 25 Most Influential Americans Apr.21, 1997. Disponível em: www.time.com/time/magazine/ article/0,9171,986206,00.html. Acesso em: jul. 2011.

TIRONI, L.; CRUZ, B. Inovação incremental ou radical: há motivos para diferenciar? abordagem com dados da Pintec. Texto para Discussão, Brasília, IPEA, n.1360, 2008.

VELHO, Léa. O papel da formação de pesquisadores no sistema de inovação. Ciência e Cultura, São Paulo, v.59, n.4, out. 2007

VIOTTI, Eduardo Baumgratz. Brasil: de política de C\&T para política de inovação? Evolução e desafios das políticas brasileiras de ciência, tecnologia e inovação In: SEMINÁRIO INTERNACIONAL: avaliação de políticas de ciência, tecnologia e inovação: diálogo entre experiências internacionais e brasileiras. Brasília: Centro de Gestão e Estudos Estratégicos, 2008. Disponível em: www.cgee.org.br/atividades/redirect.php?idProduto=5070. Acesso em: jul. 2011 .

VIOTTI, Eduardo Baumgratz. National learning systems: a new approach on technological change in late industrializing economies and evidences from the cases of Brazil and South Korea. Science, Technology and Innovation Discussion Paper, Harvard University; Center for International Development, n.12, 2001.

WHITTAKER D. H. Comparative entrepreneurship: the UK Japan and the shadow of Silicon Valley. Oxford: Oxford University Press, 2009. 


\section{INTENSIVE ENTREPRENEURSHIP IN KNOWLEDGE IN BRAZIL}

\section{Sonia Maria Karam Guimarães}

One of the surprises of the "new economy" is a increase number of micro, small and median size businesses intensives in knowledge, as well as the number of "entrepreneur-scientists" in peripheral economies, that until recently lacked innovation capability like in China, India (Saxenian 2008). Brazil faces great challenges to integrate itself to the new development paradigms, compared to its pares. Despite that intensives knowledge companies emerge ever faster over here. The article analyses the results of a research conducted among intensive in knowledge micro, small and median size businesses, placed in the technological park of the states of Rio Grande do Sul \& Santa Catarina. The data show that even limited, it is observed some positive changes in the configuration of businesses models in the investigative segments. Conclusion, thus the barriers in existence are not insurmountable, and the knowledge already learned seems to indicate processing possibilities to innovating small and median size businesses, in Brazil.

KEY Words: innovating small and median size businesses, entrepreneur-scientists, innovation, knowledge society.

\section{ENTREPRENARIAT INTENSIF DES CONNAISSANCES AU BRÉSIL}

\author{
Sonia Maria Karam Guimarães
}

L'une des surprises de la "nouvelle économie" est le nombre croissant de micro, petites et moyennes entreprises intensives en connaissance, telles que celles de "scientifiques-entrepreneurs" dans les économies périphériques qui, jusqu'à présent, n'étaient pas capables d'innover comme en Chine et en Inde (Saxenian, 2008). Le Brésil se trouve face à d'énormes défis pour s'intégrer au nouveau paradigme de développement, si on le compare à ses pairs. Malgré tout, les entreprises intensives en connaissance surgissent ici de plus en plus. L'article analyse les résultats d'une recherche faite auprès de micro, petites et moyennes entreprises intensives en connaissance localisées dans des parcs technologiques des États de Rio Grande do Sul et de Santa Catarina. Les données mettent en évidence que, même s'ils sont encore limités, on peut observer des changements positifs dans la configuration du modèle entrepreneurial du domaine étudié. On en arrive donc à la conclusion qu'on peut dépasser les barrières qui existent et l'apprentissage acquis semble indiquer qu'il y a des possibilités prometteuses pour les petites et moyennes entreprises innovatrices au Brésil.

MoTS-CLÉs: petites et moyennes entreprises intensives en connaissance, scientifique, entrepreneur, innovation, développement économique, société de la connaissace.

Sonia K. Guimarães - Doutora em Sociologia. Professora Titular do Departamento de Sociologia e do Programa de Pós Graduação em Sociologia da Universidade Federal do Rio Grande do Sul. Pesquisadora 1B CNPq. $\mathrm{PhD}$ em Sociologia pela London School of Economics and Political Science, Universidade de Londres, com estágio pós-doutoral na Sloan School of Management, MIT, Cambridge Ma., Estados Unidos. Coordena o Grupo de Pesquisa/UFRGS/CNPq Trabalho na Sociedade Contemporânea (www.ufrgs.br/ppgsocio). Autora de vários artigos em periódicos indexados nacionais e internacionais (a maioria sob o sobrenome Larangeira), em especial sobre transformações no trabalho na área de serviços (bancos e telecom), reestruturação produtiva e sindicatos. Suas investigações no presente estão voltadas para o estudo de pequenas e médias empresas intensivas em conhecimento. 
